\title{
Bacterial and Fungal Profile of External Ocular Infections in a Tertiary Care Hospital
}

\author{
C. Suja ${ }^{1 *}$, Jasmine Vinshia ${ }^{1}$ and S.S. Uma Mageswari ${ }^{2}$ \\ ${ }^{1}$ Department of Microbiology, Rajas Dental College \& Hospital, Tirunelveli, India \\ ${ }^{2}$ Departmentof Microbiology, Chettinad Hospital \& Research Institute, Chennai, India \\ *Corresponding author
}

\begin{abstract}
A B S T R A C T
The eye may be infected from external sources or through intraocular invasion of microorganisms carried by the blood stream. The common eye infections caused by bacterial and fungal pathogens are blepharitis, conjunctivitis, internal and external hordeolum, keratitis, dacryocystitis. Timely institution of appropriate therapy must be initiated to control the infections and thereby minimize the ocular morbidity. Objectives: To study the prevalence of Bacterial and Fungal etiology of External ocular infections and to study the antibiotic susceptibility Pattern of the isolated bacterial pathogens. This study was carried out at Chettinad Hospital \& Research Institute. A total of 100 patients with ocular infection attending outpatient department of ophthalmology were included in the study. Conjunctival swabs and corneal scrapings were collected and sent to the microbiology laboratory. The organisms were identified by colony morphology and appropriate biochemical reactions. Among the 100 samples 38(63.3\%) culture positive in which $21(55.2 \%)$ were bacterial isolates and 17(44.7\%) fungal isolates. Coagulase negative Staphylococcus $14(66.6 \%)$ was the commonest isolate that cause conjunctival infection followed by staphylococcus aureus $2(9.5 \%)$, Pseudomonas aeruginosa, Acenitobacter, Aeromonas, Streptococcus pneumonaiae, Klebsiella 1(4.7\%) each. The split up of fungal isolates Fusarium6 (35.2\%) followed by Aspergillus flavus 4(23.5\%), Aspergillus niger 4 (23.5\%), Aspergillus fumigatus 2 (11.7\%) and Candida albicans 1 (5.8\%). The Gram positive isolates are susceptible to Cefazolin $94.11 \%$,Vancomycin $100 \%$, Ciprofloxacin $75.25 \%$ and the Gram negative isolates were susceptible to amikacin $66.6 \%$,ciprofloxacin $66.6 \%$. Coagulase negative Staphylococci frequently causes infection of the conjunctiva and eyelids followed by Staphylococcus aureus. Similarly, Fusarium sps frequently causes corneal infection.
\end{abstract} Ke y w o r d s

\section{Introduction}

Ocular infections are common and their morbidity can vary from self-limiting, trivial infection to sight- threatening. Ocular infections can affect different eye structures; and their presentation and treatment vary accordingly. The causative agents of ocular infections can be bacteria, fungi, viruses and parasites. Pathogenic microorganisms cause diseases to the eyes due to their virulence and host's reduced resistance from many factors such as personal hygiene, living conditions, socio-economic status, nutrition, genetics, physiology, fever and age (Vaughan et al., 1992). The areas in the eye that are frequently infected are the conjunctiva, lid and cornea clinically external eye infections present as: conjunctivitis, keratitis, blepharitis, dacryocystitis and external hordeolum (Modarrres et al., 1998). 
The conjunctiva and ocular adnexae are rapidly colonized by bacteria at birth and conjunctival bacterial micro flora undergo constant turnover. The flora isolated in healthy individuals consists primarily of Diphtheroids. Species of greater virulence, such as Coagulase negative Staphylococci, Staphylococcus aureus, Streptococcus pneumonia, Pseudomonas aeruginosa, Neisseria meningitides, Neisseria gonorrheae, Haemophilus influenzae, Moraxella lacunata and Corynebacterium diphtheria have also been reported (Frederic et al., 2001).

Bacteria are the most common microorganisms that cause conjunctivitis. This is because the bacterial pathogens inhabit the ocular surface (i.e. mucous membrane of the conjunctiva), though the lysosomes and antibodies in tear and blinking mechanism keep their population in check (Idu et al., 2003). Mycotic keratitis is usually caused by filamentous fungi and occurs in conjunction with trauma to the cornea with vegetation matter. In the tropics it is common in male agricultural workers. Eye trauma is the cause of fungal keratitis in temperate areas as well. The common fungal genera involved are Fusarium, Alternaria and Aspergillus spp. (Wong et al., 1997). The ocular findings may be part of a widespread systematic infection. In deciding on appropriate treatment, both the causative pathogen and the structure affected must be considered. Differences in drug absorption, penetration, and availability to the various structures of the eye affect treatment decisions. Severity of infection, efficacy and safety of medication, and cost/ benefit ratios must be taken into consideration in choosing the proper pharmacologic management of various ocular infections.

This research, therefore, aims amongst others at evaluating the antibiotic sensitivity of the bacterial organisms isolated from the eye infections, studying the distribution of the common bacterial and fungal isolates in the clinical features- conjunctivitis, blepharitis and keratitis, the distribution of these bacterial isolates amongst age groups and the distribution of these bacterial isolates between males and females.

\section{Materials and Methods}

This study was carried out at Chettinad Hospital and Research Institute from March 2012 to March 2013.A total of 100 patients with ocular infection attending outpatient department of ophthalmology were included in the study. The samples were collected and submitted for microbiological evaluation from patients clinically diagnosed with ocular infections such as blepharitis, conjunctivitis, external and internal hordeolum, corneal ulcer, dacryocystitis. All the patients were examined on the slit-lamp biomicroscope. After detail examination samples were collected for smear and culture.

\section{Sample collection}

Collection of sample is done by ophthalmic surgeon ${ }^{(23)}$. A collection kit must readily be available and it includes:

\section{Collection of conjunctival material}

Sterile moistened cotton swab or calcium alginate swab are used. Bacterial culture medium such as BHIB or normal saline may be used for moistening the swab.

Patient is requested to look up, the lower eye lid is pulled down using thumb with an absorbing tissue paper and moistened swab is rubbed over the lower conjunctival sac from medial to lateral side and back again.

The procedure is often slightly painful.

Sterile plastic (soft) bacteriological loop may be used for collection of material

Avoid collection of tears only.

Biochemical test - Catalase, Oxidase, 
Coagulase, -Indole, Methyl red, Voges Prosauker, Triple sugar Iron, citrate, Urease, Mannitol motility medium

\section{Procedure for processing conjunctival sample}

The specimens were inoculated directly onto the blood agar, chocolate agar, Sabouraud's dextrose agar. The plates are inoculated and are incubated at $37^{\circ} \mathrm{C}$ overnight. Based on the colony morphology the pathogens were identified and biochemical test were done.

A part of the collected specimens was subjected to gram staining. A standardized protocol was followed for each ocular specimen for the evaluation of significant microbiological features (MackeyMcCartney; practical medical microbiology $\mathrm{y}^{(25)}$.

\section{Collection of corneal scrapings}

Corneal scrapping was taken in ophthalmology department under local anaesthesia i.e. $4 \%$ paracaine eye drops without preservative. Corneal scrapping is done from the leading edge and the base of the ulcer by using kimura spatula or 15 no sterile Bard Parker Surgical Blade with the help of slit lamp under aseptic conditions

\section{Procedure for processing keratitis sample}

Gram staining was performed. Culture on Blood agar in the form of ' $c$ ' shape streak. Incubate at $37^{\circ} \mathrm{C}$ for $24 \mathrm{hrs}$. Based on colony morphology bacterial pathogens were identified by biochemical reactions. Antibiotic Sensitivity is done by Kirby Bauer's Disc diffusion method.

\section{Result and Discussion}

During the study period of one year a total of 100 samples were collected from patients who are clinically diagnosed with external ocular infections. Out of 100 samples 68 samples shows positive result and the remaining 32 was culture negative. In this study, Male patients are affected more when compared to the female patients. Off the 100 patients $44 \%$ were female patients and 56\% were male patients. Both male and Female patients of age group $>60$ were highly affected with External ocular infections (Table 1).

Among the 100 samples, 65\% of samples were collected from patients with conjunctival infection such as Conjunctivitis, Blepharitis, Dacryocystitis and $35 \%$ of the sample were isolated from patients with infection of the Cornea most commonly Keratitis. The most common external ocular infection is conjunctivitis 43 followed by Cornel ulcer 23, Blepharitis 1, Dacryocystitis 1(Table 2).

Systemic disease related to eye disease:

1. Diabetic patients - 17

2. Non-Diabetic patients -83

The Corneal ulcer is mainly due to infection with agents such as foreign body / sand, thorn, paddy husk, infection with finger. In this study, most of the corneal ulceration is due to infection with paddy husk. About 8 patients were infected with Paddy husk his clearly shows that these patients were mainly from Agriculture fields (Table 3). Among the 68 culture positive samples $37(54.4 \%)$ were Bacterial isolates and 23(33.3\%) were fungal isolates (Table 4). The predominant bacterial isolate is Coagulase negative Staphylococci $18(48.8 \%)$ followed by Staphylococcus aureus 10(27\%), Pseudomonas aeruginosa $5(13 \%)$, Klebsiella 2(5.5\%), Acinetobacter 1(2.7\%), Streptococcus pneumoniae 1(2.7\%), Citrobacter (3\%), Enterobacter (3\%) (Table $5)$. The Gram positive isolates are susceptible to Cefazolin $94.11 \%$, Vancomycin $100 \%$, Ciprofloxacin $75.25 \%$, Erythromycin $76.4 \%$ 
and Clindamycin $82.35 \%$ (Figure 1). The Gram negative organisms were mostly sensitive to amikacin, Third generation cephalosporins, gentamicin, piperacillin tazobactum, carbencillin and fluroquinolones like ciprofloxacin (Figure 2).
Off the 23(33.3\%) fungal isolates Fusarium sps $11(37 \%)$ is the predominant organism followed by Aspergillus flavus (21.1\%), Aspergillus niger 4(17\%), Aspergillus fumigatus 2(18.6\%) and Candida albicans $1(4.3 \%)$ respectively (Table 6$)$.

Table.1 Age and Sex distribution

\begin{tabular}{|l|l|l|l|l|}
\hline s.no & Age & Male & Female & Total \\
\hline 1. & $0-15$ & 6 & 9 & 15 \\
\hline 2. & $15-30$ & 8 & 3 & 11 \\
\hline 3. & $30-45$ & 10 & 8 & 18 \\
\hline 4. & $45-60$ & 11 & 4 & 15 \\
\hline 5. & $>60$ & 21 & 20 & 41 \\
\hline
\end{tabular}

Table.2 Clinical conditions

\begin{tabular}{|l|l|l|}
\hline S.no & Infections & $\begin{array}{l}\text { Number of } \\
\text { samples }\end{array}$ \\
\hline 1. & Conjunctivitis & 43 \\
\hline $\mathbf{2}$ & Blepharitis & 1 \\
\hline 3. & Dacryocystitis & 1 \\
\hline 4. & Cornel ulcer & 23 \\
\hline
\end{tabular}

Table.3 Injuring agent in case of cornel ulcer

\begin{tabular}{|l|l|l|}
\hline S.no & Nature of agent & Number \\
\hline 1. & foreign body/sand & 5 \\
\hline 2. & paddy husk & 7 \\
\hline 3. & thorn & 2 \\
\hline 4. & others & 2 \\
\hline 5. & no agent & 8 \\
\hline
\end{tabular}


Table.4 Total number of bacterial isolates

\begin{tabular}{|l|l|l|}
\hline S.no & Organisms & Number (\%) \\
\hline $\mathbf{1}$ & CONS & $16(43.24 \%)$ \\
\hline $\mathbf{2}$ & Staphylococcus aureus & $10(27 \%)$ \\
\hline $\mathbf{3}$ & Pseudomonas aeruginosa & $5(13 \%)$ \\
\hline $\mathbf{4}$ & Acinetobacter & $1(2.7 \%)$ \\
\hline $\mathbf{5}$ & Streptococcus pneumoniae & $1(2.7 \%)$ \\
\hline $\mathbf{6}$ & Klebsiella & $2(5.4 \%)$ \\
\hline $\mathbf{7}$ & Citrobacter & $1(2.7 \%)$ \\
\hline $\mathbf{8}$ & Enterobacter & $1(2.7 \%)$ \\
\hline
\end{tabular}

Table.5 Total number of fungal isolates

\begin{tabular}{|l|l|l|}
\hline S.no & Organisms & Number (\%) \\
\hline $\mathbf{1}$ & Fusarium sps & $11(37 \%)$ \\
\hline $\mathbf{2}$ & Aspergillus flavus & $5(21 \%)$ \\
\hline $\mathbf{3}$ & Aspergillus niger & $4(17 \%)$ \\
\hline $\mathbf{4}$ & Aspergillus fumigatus & $2(18.6 \%)$ \\
\hline $\mathbf{5}$ & Candida albicans & $1(4.3 \%)$ \\
\hline
\end{tabular}

Fig.1 Antibiotic sensitive pattern of gram positive cocci

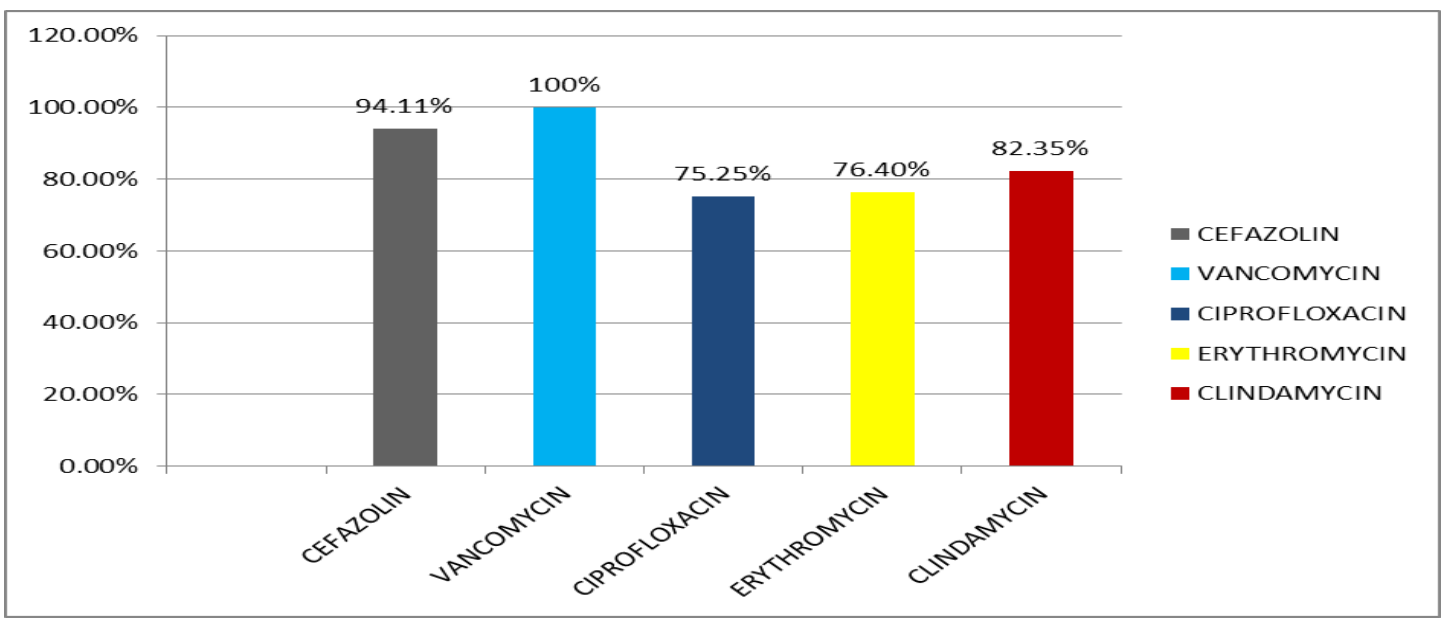


Fig.2 Antibiotic sensitive pattern of gram negative bacilli

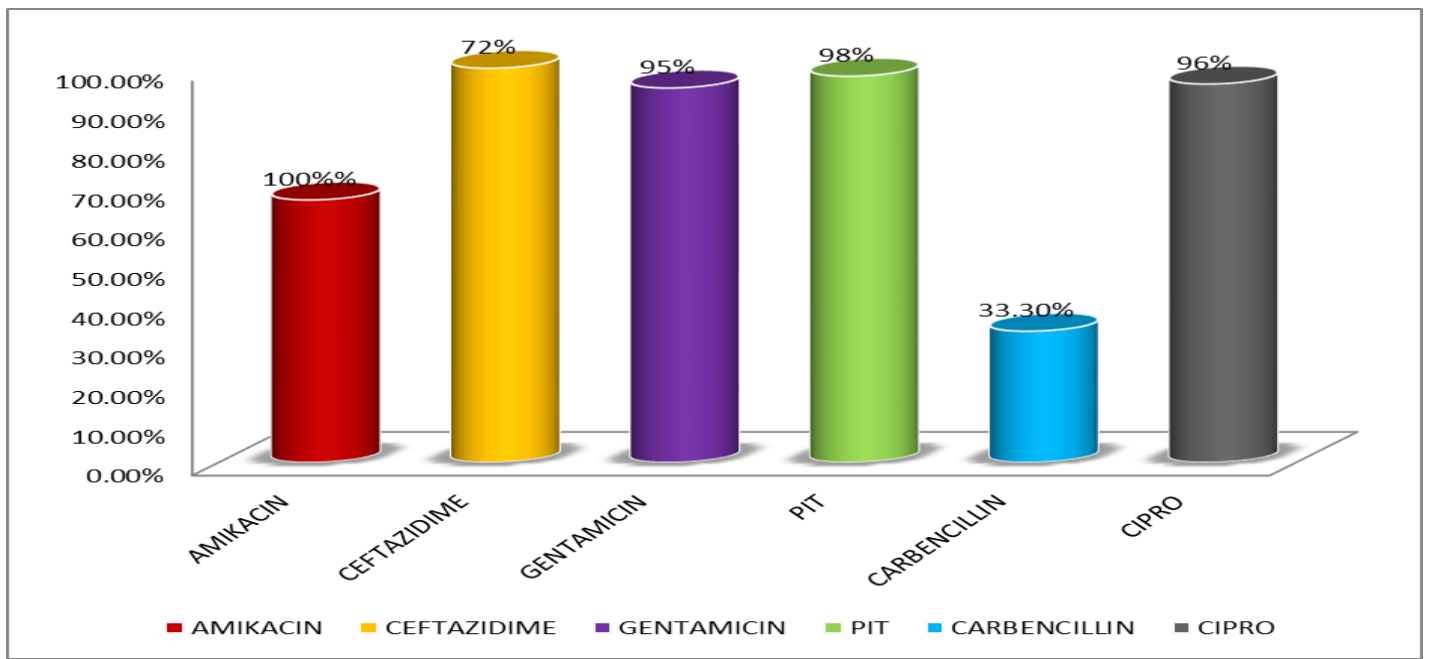

A combination of mechanical, anatomic, immunologic and microbiologic factor prevents Ocular infections and do not allow the survival of pathogenic species in eye. However in certain circumstances they gain accesses to the eye and cause infection. Prompt and specific therapy can be instituted if the microbes can be isolated and their susceptibility to the antimicrobials is known. However, the ability to isolate the causative organism depends on a variety of factors including the amount of inoculums, the site from which it is taken, the media used for culture and also on the empirical treatment received before collection of the samples. Hence, the culture-positivity varies from Centre to Centre (Bharati et al., Bacteriology of Ocular infections.).

During the study period of one year out of 68 culture positive cases, $56 \%$ were in male sex and the remaining $44 \%$ were in the female sex. This obvious preponderance of male sex is due to their outdoor activities and is prone for injury. Most of them belong to low socioeconomic group. (Srinivasan et al., ${ }^{(29)}$ ). In this study a total of 68 cases show culture positivity out of which $54.4 \%$ were bacterial isolate and $33.3 \%$ were fungal isolates. The most common Bacterial Ocular infection is
Conjunctivitis, Blepharitis and Dacryocystitis. Fungi were identified as the predominant aetiological agent for corneal ulceration (Sundaram et al.,). Bacterial conjunctivitis is the most commonly seen external ocular infection as seen in other studies (Vaughan et al.,). Out of 37 bacterial isolates, Coagulase negative Staphylococci (48.8\%) is the predominant organism causing Conjunctivitis i.e. Staphylococci epidermidis causing this infection (Das et al., ). The second most organism causing bacterial conjunctivitis is Staphylococcus aureus (27\%) followed by Pseudomonas aeruginosa (13\%), Streptococcus pneumoniae (2\%), Klebsiella, Acinetobacter, Citrobacter, Enterobacter 3\% each. The causes of bacterial conjunctivitis is the alteration in the normal flora, which can occur by external contamination, by spread from adjacent sites or via blood-born path way and disruption of epithelial layer covering the conjunctiva (Bauman, 2010).

The Antimicrobial sensitivity pattern of Gram positive cocci and Gram negative bacilli shows similar results with other studies (Bharati et al.,). The Gram positive isolates are susceptible to Cefazolin $94.11 \%$, Vancomycin $100 \%$, Ciprofloxacin $75.25 \%$, Erythromycin $76.4 \%$, Clindamycin $82.3 \%$ and 
the Gram negative isolates were susceptible to Amikacin 100\%, ceftazidime $66.6 \%$, Gentamicin 95\%, Ciprofloxacin 96\%, piperacillin-tazobactum $\quad 98 \%$,carbencillin $33.3 \%$. Resistance and sensitivity based on in vitro testing may not reflect the true clinical resistance and response to an antibiotic because of the host factors and penetration of the drug. Vancomycin revealed a highest efficacy against Gram positive cocci isolates compared with other antibacterial agents. Vancomycin is a glycopeptide; it inhibits early stages in the cell wall mucopeptide synthesis and it exhibits greatest potency against Gram positive Ocular isolates. Out of 23 fungal isolates, Fusarium sps (37\%) is the common organism causing corneal ulceration followed by Aspergillus flavus (22\%) but in most of the studies Aspergillus flavus was isolated as the predominant organism causing corneal ulcer. The prevalence rate from other studies are $25-35 \%$ in Pondicherry,50\% in Hyderabad, 64\% in Chennai (Venugopal et al., $\left.{ }^{(30)}\right)$. The other organisms for corneal ulcers are similar when compared with other studies as Aspergillus niger (17\%), Aspergillus fumigatus (18\%) and Candida albicans (4\%). Venugopal et al., reported that men are more susceptible to corneal ulcer than female. In a study with 3528 cases in Delhi Mycotic Keratitis seems to be prevalent in males, in farmers and the most common predisposing factor remains trauma to the cornea (Chander J Sharma ${ }^{(31)}$ ).

In conclusion, coagulase negative Staphylococci frequently causes infection of the conjunctiva and eyelids followed by Staphylococcus aureus. Similarly, Fusarium sps frequently causes infection of the cornea most commonly corneal ulcer. Infections of the cornea due to filamentous fungi are a frequent cause of corneal damage in developing countries in the tropics and are difficult to treat. Microscopy is an essential tool in the diagnosis of these infections.

\section{Acknowledgement}

I would like to thank my teachers, my family and my whole department for their guidance and extended help in completion of my research work.

\section{References}

1. Vaughan D, Asbury $\mathrm{T}$ and Riodan $\mathrm{P}$. General Ophthalmology, Lange Medical publication, $15^{\text {th }}$ ed. 1996; 96-67.

2. Modarrres Sh, Lasheii J and Nasser O. Bacterial etiologic agents of ocular infection in children in the Islamic Republic of Iran. East Med Heal J., 1998; 4: 44-49.

3. Frederic S, Olivier B, Leonidas $Z$ and Yan GC. Bacterial keratitis: a prospective clinical and microbiological study. $\mathrm{Br} J$ Ophthalmol., 2001; 85:842-847.

4. Idu F and Odjimogho K, Stella S. Susceptibility of conjunctival bacterial pathogens to fluoroquinolones. A comparative study of ciprofloxacin, norfloxacin and ofloxacin. $J$ of Health and Allied Sci., 2003;2:3-7

5. Wong TK, Fong $S$ and Tan DT. Clinical and microbial spectrum of fungal keratitis in Singapore: A 5-year retrospective study. Int. Ophthalmol. 1997; 21:127-130.

6. Williamsons on-Noble FA, Sorsby A. Etiology of the eye diseases; developmental defects; heredity. In: Conrad B, editor. The Eye and Its Diseases. 2nd ed. Philadelphia: W. B. Saundars Company; 1950. pp. 309-21.

7. Sihota R, Tandon R, editors. New Delhi: Elsevier; Parsons' Diseases of the Eye; 20th ed, 2007 pp. 155-376,423-69

8. M Srinivasan, Christine A Gonzales, Celine George, Vicky Cevallos, Jeena M Mascarenhas, B Asokan, John Wilkins, Gilbert Smolin, John P Whitcher; Epidemiology and aetiological diagnosis of corneal ulceration in Madurai, south 
India, British Journal of Ophthalmology 1997; 81: 965-971.

9. Benz MS, Scott IU, Flynn HW, Jr, Unonius N, Miller D. Endophthalmitis isolates and antibiotic sensitivities: A 6year review of culture-proven cases. Am J Ophthalmol. 2004; 137: 38-42.

10. Chalita MR, Hofling-Lima AL, Paranhos A, Jr, Schor P, Belfort R., Jr Shifting trends in in-vitro antibiotic susceptibilities for common ocular isolates during a period of 15 years. Am J Ophthalmol. 2004; 137: 43-51.

11. Leck AK, Thomas PA, Hagan M, Kaliamurthy J, Ackuaku E, John M, et al., Aetiology of suppurative corneal ulcers in Ghana and south India, and epidemiology of fungal keratitis. $\mathrm{Br} \mathrm{J}$ Ophthalmol. 2002; 86:1211-5.

12. Singh G, Palanisamy M, Madhavan B, Rajaraman R, Narendran K, Kour A, et al., Multivariate analysis of childhood microbial keratitis in South India. Ann Acad Med Singapore. 2006; 35: 185-9.

13. Anand AR, Therese KL, Madhanvan HN. Spectrum of aetiological agents of postoperative endophthalmitis and antibiotic susceptibility of bacterial isolates. Indian J Ophthalmol. 2000; 48:123-8.

14. Lalitha P, Rajagopalan J, Prakash K, Ramasamy R, Venkatesh P, Srinivasan M. Post cataract endophthalmitis in South India. Ophthalmology. 2005; 112:188590.

15. Bharathi MJ, Ramakrishnan R, Vasu S, Meenakshi R, Palaniappan R. In-vitro efficacy of antibacterials against bacterial isolates from corneal ulcers. Indian $\mathbf{J}$ Ophthalmol. 2002;50:109

16. Sharma S, Kunimoto DY, Garg P, Rao GN. Trends in antibiotic resistance of corneal pathogens: Part I. An analysis of commonly used ocular antibiotics. Indian J Ophthalmol. 1999; 47:95-100.

17. Thylefors B, Negrel AD and
Pararajasegaram R. Global data on blindness. Bull World Health Organ 1995; 73:115-21.

18. World Health Organization. Preventing blindness in children Report of a WHO/IAPB scientific meeting. WHO/PBL/00.77. Geneva: WHO, 2000

19. Kello AB and Gilbert C. Causes of severe visual impairment and blindness in children in schools for the blind in Ethiopia. $\quad B r \quad J$ Ophthalmol., 2003 ; 87:526-530.

20. Gordon External eye infections. Comm Eye Health 1999; 12: 17-32.

21. Upadhyay MP, Karmacharya PC, Koirala, Shah DN, Shakya S and Shresth JK. The Bhaktapur eye study: ocular trauma and antibiotic prophylaxis for the prevention of corneal ulceration in Nepal. $\mathrm{Br} J$ Ophthalmol., 2001; 85:388-92.

22. Tabbara F and Robert A. Infections of the eye 2nd the eye institute, Riyadh, Saudi Arabia 1995. pp 3, 98, 556.

23. Microbiological procedures for diagnosis of Ocular infections K. Lily Therese \& H.N. Madhavan L \& T Microbiology Research centre Vision Research foundation.

24. Guidelines for the management of cornel ulcer: World Health Organization; Regional Office for South-East Asia 2004.

25. Collee, J. G, Juguid J. P, Fraser, D. G, marmion, B. P. (1989): Mackie and McCartney Practical medical Microbiology 13th Ed. Churchill Livingstone

26. Washington C. Winn, Elmer William Koneman, Lippincott Williams \& Wilkins, Koneman's Color Atlas and Textbook of Diagnostic Microbiology, 6e, 2006 Pp. 211, 303, 623, 672.

27. Bauer AW, Kirby WM and Sherries JC. Antibiotic susceptibility testing by a standardized single disk method. Amer J Clinpathol., 1996; 45: 493. 
28. Jagdish Chander, Textbook of Medical Mycology $3^{\text {rd }}$ edition 2008 Pp. 53, 266, 343.

29. M Srinivasan, Christine A Gonzales, Celine George, Vicky Cevallos, Jeena M Mascarenhas, B Asokan, John Wilkins, Gilbert Smolin, John P Whitcher; Epidemiology and aetiological diagnosis of corneal ulceration in Madurai, south
India, British Journal of Ophthalmology 1997; 81: 965-971.

30. Chander J Sharma A. Prevalence of fungal corneal ulcers in Northern India. Infection 1994, 22: 207-209

31. Venugopal PL, Venugopal TL, Gomathi A, et al., Mycotic keratitis in Madras. Indian J PatholMicrobiol 1989; 32:190-7.

\section{How to cite this article:}

Suja, C., Jasmine Vinshia and Uma Mageswari, S.S. 2019. Bacterial and Fungal Profile of External Ocular Infections in a Tertiary Care Hospital. Int.J.Curr.Microbiol.App.Sci. 8(02): 2081-2089. doi: https://doi.org/10.20546/ijcmas.2019.802.241 